\title{
Significant costs and low utilization of stored peripheral blood stem cells for salvage autologous transplant in multiple myeloma patients including those meeting mSMART criteria
}

\author{
Nausheen Ahmed $\mathbb{D}^{1} \cdot$ Lucy Li $^{2} \cdot$ Patricio Rojas ${ }^{1} \cdot$ Fahrettin Covut ${ }^{1} \cdot$ Jane Reese-Koc ${ }^{1} \cdot$ Merle Kolk $^{1} \cdot$ Ehsan Malek $^{1} \cdot$ \\ Leland Metheny $\mathbb{( i D}^{1} \cdot{\text { Timothy } \mathrm{O}^{\prime} \text { Brien }^{1} \cdot \text { Paolo Caimi }}^{1} \cdot$ Marcos de Lima $\mathbb{D}^{1} \cdot$ Brenda W. Cooper $^{1}{ }^{1}$
}

Received: 1 August 2020 / Revised: 21 December 2020 / Accepted: 11 January 2021 / Published online: 29 January 2021

(c) The Author(s) 2021. This article is published with open access

\section{To the Editor:}

Autologous stem cell transplantation (ASCT1) plays an important role in the management of patients with multiple myeloma (MM) and remains relevant in the era of novel therapeutics $[1,2]$.

A second autologous transplant, usually after reinduction therapy, is a recommended strategy at the time of relapse, with improved progression-free survival (PFS) and possibly improved overall survival (OS) in select patients compared to chemotherapy in some series [3-5]. Due to potential difficulties harvesting adequate peripheral blood stem cells (PBSC) at the time of relapse and published clinical guidelines our institutional policy has been to collect and cryopreserve sufficient hematopoietic progenitor cells whenever feasible to allow for salvage transplant (ASCT2) at the time of relapse. The utilization of salvage autologous transplants and associated costs were analyzed in a cohort of 169 MM patients who received ASCT1 between January 2009 and December 2017. We focus, in particular on the subgroup of patients who met the mSMART criteria for ASCT2 defined as relapse $>36$ months with the use of maintenance therapy or 18 months without the use of maintenance therapy, respectively [6].

Patient demographic data, disease-related information, and cellular therapy data were obtained from institutional databases, the Stem Soft Database and chart review. Follow-up was until death or last contact with the data

Brenda W. Cooper

Brenda.Cooper@UHhospitals.org

1 Seidman Cancer Center, University Hospitals, Cleveland Medical Center, Case Western Reserve University, Cleveland, OH, USA

2 Case Western Reserve University, Cleveland, OH, USA cutoff being January 1, 2020. Patients were censored at their last visit if they were lost to follow-up. This study was approved by the Institutional Review Board at University Hospitals, Cleveland Medical Center, and due to the nature of the study, patient consent was not required. ASCT2 was offered based on patient and physician preference.

PBSC were mobilized using cyclophosphamide (2-4 gm/ $\mathrm{m}^{2}$ ) plus filgrastim $(n=24)$, filgrastim at a dose of 10-16 $\mu \mathrm{gm} / \mathrm{kg}$ with leukapheresis starting on day $5(n=19)$, or filgrastim plus plerixafor $(n=123)$ and was not available for three patients. The minimum acceptable CD34 target collection goal was $5 \times 10^{6} \mathrm{CD} 34+$ cells per kilogram of actual body weight with extra days of collection defined as one or more additional days of leukapheresis for the sole purpose of obtaining $\geq 2 \times 10^{6} \mathrm{CD} 34$ cells $/ \mathrm{kg}$ for storage. No additional collection charges were tabulated for patients who were unable to store adequate progenitor cells (i.e., $<2 \times 10^{6} \mathrm{PBSC} / \mathrm{kg}$ ) or for patients who achieved their target goal in one pheresis session.

The median age of the 169 patients was 61 years (36-77 years) and the median time from diagnosis to first autograft was 9 months (range 3-115) and was more than 2 years in 14 patients $(8.2 \%)$. Overall, 100 patients $(59 \%)$ received one treatment regimen, $46(27 \%)$ received two regimens and $23(14 \%)$ received three or more regimens prior to autograft and $95 \%$ of patients had a clinical response prior to undergoing ASCT1. Adequate PBSCs for storage was achieved in a single leukapheresis for $30.2 \%$ of patients who received plerixafor and filgrastim compared to less than $10 \%$ using chemotherapy plus filgrastim or filgrastim alone $\left(\chi^{2}=21.9, p<0.05\right.$, Table 1a). The range of PBPC mobilized was $2.25-82.32 \times 10^{6} \mathrm{CD} 34+$ cells $/ \mathrm{kg}$ (median $9.32 \times 10^{6}$ ) and 18 and 5 patients, respectively, failed to mobilize adequate stem cells or had insufficient information, leaving a total of 146 patients available for analysis. 
Table 1 Apheresis procedures and costs. (a) Apheresis procedures performed according to mobilization strategy ( $n=169$ patients). (b) Associated costs for stem cell collection and storage $(n=146)$.

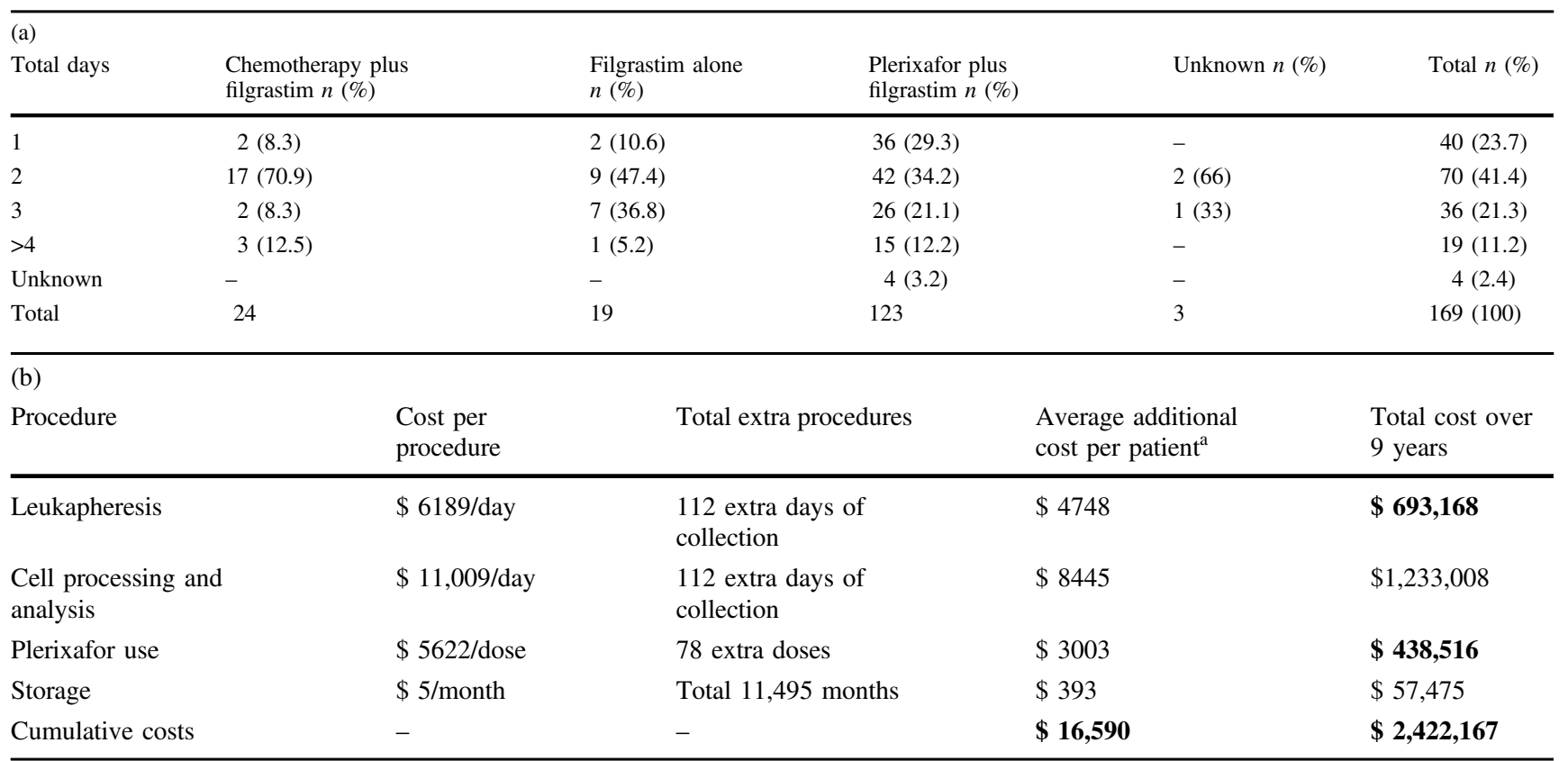

${ }^{a}$ Costs were calculated for 146 patients according to 2019 institutional charge master.

(a) Total days of collection for 169 patients according to mobilization strategy.

(b) Cost of extra collection for stem cell storage according to 2019 Institutional charge master.

At the time of data cutoff, only 3/146 (2\%) patients with adequate stored PBSC received a salvage transplant. Overall, 129 patients (median follow-up 41 months) had complete follow-up information. Median PFS was 29 months among the 17 patients who did not receive maintenance therapy and 46 months in the 112 patients who received maintenance therapy $(p=0.11)$. At the time of this publication, $11 / 17$ patients who did not receive maintenance therapy and 66/112 patients who received maintenance therapy relapsed, of whom 5 and 23 (total 28 patients) met mSMART criteria. Only three patients underwent ASCT2, (one of whom with relapse at 30 months did not meet mSMART criteria), experienced disease progression within 5-18 months and survived 25, 25, and 49 months after ASCT2. In comparison, median time to next treatment for the non-transplant cohort was 19 months, median survival was 45 months, and 12 patients were alive at data cutoff.

Figure 1 shows the distribution of 112 additional leukapheresis procedures in the 146 patients who had adequate cells stored for a second transplant. Costs associated with these extra collections tabulated for the entire cohort and per patient are shown in Table $1 \mathrm{~b}$.

We followed a large cohort of patients who received ASCT1 at our institution between 2009 and 2017 and with a median follow-up of 41 months, we found that only $3 /$ 146 patients $(2 \%)$ who had available stored PBSCs

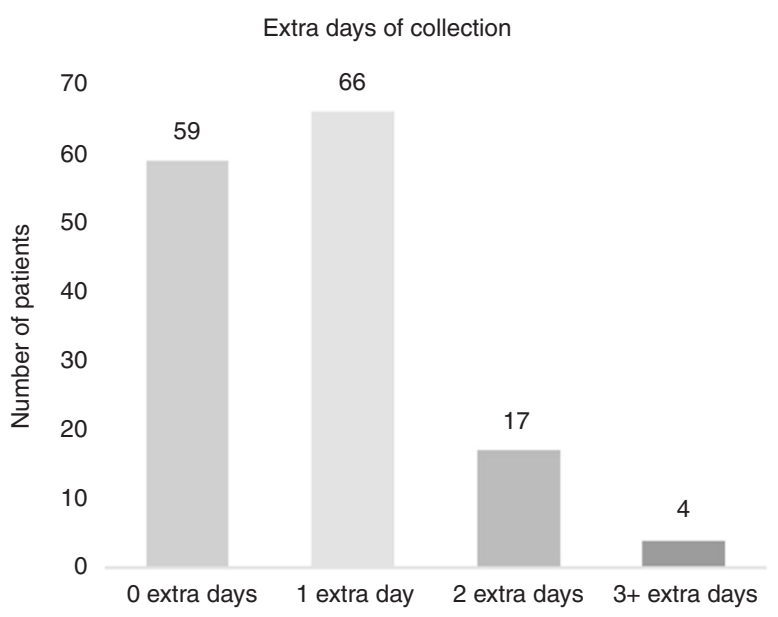

Fig. 1 Extra days of collection to obtain adequate cells for storage. Extra days of collection required for patients to collect $\geq 2 \times 106$ CD34 + cells $/ \mathrm{kg}$ for storage. The total number of extra days of collection was 112 days. 146 patients were included in this sample. 23 patients were excluded from the analysis due to failure to mobilize enough stem cells for storage $(n=18)$, or missing cell storage data $(n=5)$.

underwent a salvage ASCT, leaving 98\% of collected products unused. When we focused our analysis among the patients who met the more stringent mSMART criteria, only $3 / 28$ patients (including 1 of who relapsed at 
30 months) actually received ASCT2, leaving 90\% of products unused in this more select group. Furthermore, among the 26 patients who met the mSMART criteria, sequential treatment with available novel therapeutics after relapse appeared to have non-inferior outcomes to ASCT2 in terms of time to next treatment and OS at 19 months and 45 months, respectively.

Due to the retrospective nature of our study, patient and physician factors that determined the selection of salvage strategy including quality of life concerns [7], could not be determined. Our data, however, are consistent with the utilization of salvage transplants worldwide which show a steady decline in the use of salvage ASCT $[8,9]$ This may be in part, due to the availability of novel salvage strategies as well as limited benefit, particularly after the failure of maintenance therapy [10].

The additional cost of collecting and storing these products totaled more than 2 million dollars, with an average additional cost per patient of US $\$ 16,590$. Our costs are in line with those recently reported by others $[9,11]$. Although the costs of obtaining and storing additional PBSCs is modest in the context of other medical treatments for these patients, this practice may add unnecessary cost burden to individual institutions.

At the time of this report about half of the patients continue to be free from relapse and 22 patients are within 3 years of ASCT1 and still have the option to use their cryopreserved products. In our study, none of the patients received stored stem cell products to "refresh" the bone marrow to allow further treatments in the setting of poor marrow reserve, which is another potential use of these products.

Given the limited use of salvage transplantation, the universal practice of collecting adequate PBSC for an initial and salvage transplant should be re-evaluated. Noting difficulties of remobilization after autologous transplantation ideally, a subset of patients could be selected based on pretransplant clinical and laboratory parameters, such as minimal residual disease testing and planned maintenance strategies to determine the population of patients who would be more likely to utilize ASCT2 at the time of relapse [12].

Author contributions NA and LL contributed equally in primary authorship. PA, FC, MK, and PC: data collection and analysis. TO, EM, LM, and ML: patients and manuscript review. BWC: senior author.

\section{Compliance with ethical standards}

Conflict of interest The authors declare that they have no conflict of interest.

Publisher's note Springer Nature remains neutral with regard to jurisdictional claims in published maps and institutional affiliations.
Open Access This article is licensed under a Creative Commons Attribution 4.0 International License, which permits use, sharing, adaptation, distribution and reproduction in any medium or format, as long as you give appropriate credit to the original author(s) and the source, provide a link to the Creative Commons license, and indicate if changes were made. The images or other third party material in this article are included in the article's Creative Commons license, unless indicated otherwise in a credit line to the material. If material is not included in the article's Creative Commons license and your intended use is not permitted by statutory regulation or exceeds the permitted use, you will need to obtain permission directly from the copyright holder. To view a copy of this license, visit http://creativecommons. org/licenses/by/4.0/.

\section{References}

1. Cavo M, Gay F, Beksac M, Pantani L, Petrucci MT, Dimopoulos MA, et al. Autologous haematopoietic stem-cell transplantation versus bortezomib-melphalan-prednisone, with or without bortezomib-lenalidomide-dexamethasone consolidation therapy, and lenalidomide maintenance for newly diagnosed multiple myeloma (EMN02/HO95): a multicentre, randomised, open-label, phase 3 study. Lancet Haematol. 2020;7:e456-e68.

2. Attal M, Lauwers-Cances V, Hulin C, Leleu X, Caillot D, Escoffre M, et al. Lenalidomide, bortezomib, and dexamethasone with transplantation for myeloma. N. Engl J Med. 2017;376:1311-20.

3. Cook G, Ashcroft AJ, Cairns DA, Williams CD, Brown JM, Cavenagh JD, et al. The effect of salvage autologous stem-cell transplantation on overall survival in patients with relapsed multiple myeloma (final results from BSBMT/UKMF Myeloma X Relapse [Intensive]): a randomised, open-label, phase 3 trial. Lancet Haematol. 2016;3:e340-51.

4. Michaelis LC, Saad A, Zhong X, Le-Rademacher J, Freytes CO, Marks DI, et al. Salvage second hematopoietic cell transplantation in myeloma. Biol Blood Marrow Transpl. 2013;19:760-6.

5. Kumar SK, Callander NS, Adekola K, Anderson L, Balijevic M, Campagnaro E, et al. Multiple Myeloma, Version 3.2021, J Natl Compr Can Netw. 2020;18:1685-1717.

6. Gonsalves WI, Buadi FK, Ailawadhi S, Bergsagel PL, Chanan Khan AA, Dingli D, et al. Utilization of hematopoietic stem cell transplantation for the treatment of multiple myeloma: a Mayo Stratification of Myeloma and Risk-Adapted Therapy (mSMART) consensus statement. Bone Marrow Transplant. 2019;54:353-67.

7. Ahmedzai SH, Snowden JA, Ashcroft AJ, Cairns DA, Williams C, Hockaday A, et al. Patient-reported outcome results from the open-label, randomized phase III myeloma $\mathrm{X}$ trial evaluating salvage autologous stem-cell transplantation in relapsed multiple myeloma. J Clin Oncol. 2019;37:1617-28.

8. Giralt S, Garderet L, Durie B, Cook G, Gahrton G, Bruno B, et al. American society of blood and marrow transplantation, european society of blood and marrow transplantation, blood and marrow transplant clinical trials network, and international myeloma working group consensus conference on salvage hematopoietic cell transplantation in patients with relapsed multiple myeloma. Biol Blood Marrow Transpl. 2015;21:2039-51.

9. Phipps C, Linenberger M, Holmberg LA, Green D, Becker P, Connelly-Smith L, et al. Utilization of stored autologous PBSCs to support second autologous transplantation in multiple myeloma patients in the era of novel agent therapy. Bone marrow Transplant. 2015;50:663-7.

10. Goldschmidt H, Baertsch MA, Schlenzka J, Becker N, Habermehl C, Hielscher T, et al. Salvage autologous transplant and lenalidomide maintenance vs. lenalidomide/dexamethasone for relapsed 
multiple myeloma: the randomized GMMG phase III trial ReLApsE. Leukemia. 2020. https://doi.org/10.1038/s41375-0200948-0.

11. Shah EE, Young RP, Wong SW, Damon LE, Wolf JL, Shah ND, et al. Impact of plerixafor use at different peripheral blood CD34 $(+)$ thresholds on autologous stem cell collection in patients with multiple myeloma. Biol Blood Marrow Transpl. 2020;26:876-83.

12. Munshi NC, Avet-Loiseau H, Rawstron AC, Owen RG, Child JA, Thakurta A, et al. Association of minimal residual disease with superior survival outcomes in patients with multiple myeloma: a meta-analysis. JAMA Oncol. 2017;3:28-35. 